\title{
O POSICIONAMENTO COMPETITIVO DOS INTERNATIONAL FREIGHT FORWARDERS PELA ÓTICA DOS EXPORTADORES GAÚCHOS
}

\section{THE INTERNATIONAL FREIGHT FORWARDERS COMPETITIVE POSITIONING BY RIO GRANDE DO SUL EXPORTERS PERCEPTION}

\author{
Guilherme Bergmann Borges Vieira ${ }^{1}$; Carlos Honorato Schuch Santos ${ }^{2}$ \\ ${ }^{1}$ Universidade de Caxias do Sul - UCS - Caxias do Sul / RS \\ gbvieira@cpovo.net \\ ${ }^{2}$ Universidade Federal de Santa Maria - UFSM - Santa Maria / RS \\ chonorato@terra.com.br
}

\begin{abstract}
Resumo
O presente estudo buscou identificar o posicionamento competitivo dos International Freight Forwarders (IFFs) com base na demanda dos exportadores gaúchos usuários desse tipo de serviço. Tais prestadores de serviços logísticos, também conhecidos como agentes internacionais de carga, têm importância crucial no que diz respeito à correta e eficiente condução do trânsito internacional de mercadorias, principalmente considerando a atual complexidade e amplitude das operações logísticas globais. Para tanto, tendo como base um modelo conceitual de análise dos International Freight Forwarders, elaborado por meio de revisão da literatura da área em estudo, foi desenvolvido e enviado um questionário para uma amostra de empresas exportadoras gaúchas, extraída da base de dados da Federação das Indústrias do Estado do Rio Grande do Sul (Fiergs). Recebidos os questionários e tabulados os dados, os mesmos foram submetidos a procedimentos de estatística descritiva e à análise de regressão linear múltipla. Com isso, pôde-se analisar a adequação do posicionamento competitivo dos IFFs à demanda dos exportadores pertencentes à amostra e identificar os fatores determinantes de tal posicionamento. Os resultados obtidos são relevantes e dão suporte à análise do mercado gaúcho de IFFs, à concepção de estratégias por parte dos IFFs e à escolha desses prestadores de serviços por parte dos usuários.
\end{abstract}

Palavras-chave: prestadores de serviços logísticos; agentes internacionais de carga, posicionamento competitivo.

\section{Introdução}

A indústria, na pós-modernidade, converteu a inovação tecnológica em um princípio permanente de produção industrial (ANDERSON, 1999). Assim, a inovação deixou de ser uma alternativa e passou a ser uma necessidade. É preciso entender, no entanto, que essa inovação não ocorre apenas no processo produtivo ou nos produtos. Mudanças na arquitetura organizacional, no marketing, nos programas de recursos humanos (POSSAS, 1999) e, especialmente, nos canais de distribuição, por meio de relações contratuais privilegiadas com fornecedores, usuários e operadores logísticos, são formas de inovar e gerar competitividade (SIMCHI-LEVI; KAMINSKY; SIMCHI- 
LEVI, 2004). Nesse sentido, Avila (2006) afirma que se está, hoje, no que se chama de quinta fase do Supply Chain Management (SCM), a qual está baseada nas seguintes características: i) integração total da cadeia de valores; e ii) parcerias duradouras, porém flexíveis e adaptáveis.

É nesse cenário complexo (ALBA, 2006) que tem se desenvolvido o mercado dos Prestadores de Serviços Logísticos (PSLs) no Brasil. Empresas de diferentes setores e regiões, após otimizarem suas rotinas internas de produção (Just in Time, Teoria das Restrições, Reengenharia...), fragmentaram seus processos de produção por meio da terceirização e, principalmente, passaram a subcontratar grande parte de suas atividades logísticas.

Essa tendência beneficiou o surgimento de novas empresas de logística no mercado, aumentando a concorrência. E esse aumento da concorrência induziu as empresas a se estruturarem melhor e a conhecerem mais a fundo seu mercado de atuação, as estratégias adotadas por seus concorrentes e os aspectos considerados por seus clientes no momento de contratar um prestador de serviços.

Todos esses fatores fazem com que os PSL's tenham que conhecer o posicionamento competitivo adotado por seus concorrentes e, principalmente, sua adequação às demandas dos clientes, visando adotar ações eficazes no sentido de aumentar a competitividade.

Sabe-se, no entanto, que essa busca não garante o sucesso se for investigado apenas o “pensamento consciente do consumidor” (ZALTMAN, 2004, p. 90). Por isso é que se faz necessário o acesso tanto aos pensamentos quanto aos sentimentos inconscientes dos consumidores, esses últimos decorrentes tanto de sua história como das características do entorno em que estão inseridos. E é em função disso que Milan (2006) afirma que não basta apenas copiar concorrentes bemsucedidos. Há que se ter a convicção de que a empresa, orientada para o mercado (DAY, 2001), poderá melhor entender e atender seus clientes, construindo uma oferta de valor agregado, valor este percebido pelos clientes, fazendo com que, por meio de diferenciais competitivos, os clientes atuais mantenham sua preferência por determinado fornecedor e que novos clientes se sintam atraídos por esse tipo de oferta.

Com base nesse contexto, o presente estudo oportuniza uma visão das estratégias competitivas adotadas pelos International Freight Forwarders (IFFs) atuantes no mercado gaúcho, com base em dados obtidos dos exportadores usuários desse tipo de serviço.

O estudo justifica-se pela importância dos IFFs no comércio exterior, pois executam uma variedade de funções que facilitam a movimentação de embarques internacionais (MURPHY; DALEY, 1997); pela crescente terceirização das atividades logísticas no contexto do comércio internacional, devido ao aumento da importância e da complexidade de tais atividades e à preocupação com um melhor conhecimento das mesmas (FLEURY; RIBEIRO, 2001b) e pela relativa escassez na literatura de estudos específicos sobre o posicionamento competitivo dos IFFs. 
Dentro desse contexto, o estudo foi norteado pelas seguintes questões: Quais os tipos de estratégia e posicionamento competitivo adotados pelos IFFs atuantes no mercado gaúcho? Considerando essa tipologia, como se revela a preferência dos usuários dos serviços em termos de contratação de IFFs? Para responder a essas questões, o objetivo estabelecido foi o de avaliar o posicionamento competitivo dos IFFs atuantes no mercado gaúcho, tendo como base as preferências declaradas pelas empresas exportadoras usuárias desse tipo de serviço.

\section{Revisão bibliográfica}

Segundo a International Federation of Freight Forwarders Associations (FIATA), o agenciamento de cargas e a prestação de serviços logísticos são atividades de qualquer natureza relacionadas ao transporte (executado de modo uni ou multimodal), tais como consolidação, armazenagem, manuseio, embalagem ou distribuição de mercadorias e seus serviços secundários, incluindo desembaraço aduaneiro e assuntos fiscais, emissão de certificados para propósitos oficiais, contratação de seguro e obtenção de pagamentos ou documentos relativos à mercadoria. $\mathrm{O}$ agenciamento de cargas, ou freight forwarding, também inclui serviços de informação e comunicação conectados ao transporte, manuseio ou armazenagem da carga.

Segundo a FIATA (1980) apud Henrich (1998), o IFF existe desde o século X. No início de suas atividades, ele estava vinculado às mercadorias como um agente comissionado, executando, em nome de um produtor, todas as operações de importação e exportação, no tocante a embarque e desembarque, liberação alfandegária, armazenagem, transporte, venda e, até mesmo, em processos relacionados ao pagamento e cobrança das mercadorias. No começo do século XVIII, tornou-se mais comum a utilização de "consolidações" de carga, passando os IFFs a responsabilizarem-se pelas atividades de coletar e agrupar mercadorias de diversos embarcadores para o mesmo destino.

Hoje em dia, mais e mais empresas estão respondendo aos desafios inerentes à internacionalização dos negócios e utilizando-se de prestadores de serviços logísticos em atividades que vão além de suas competências essenciais, em busca de flexibilidade e de capacitações fora de suas especialidades (FLEURY; LAVALLE, 1997). Nesse contexto, os IFFs têm como objetivo coordenar e dar apoio em todas as fases de movimentação de cargas, desde as instalações do exportador até o destino final (STOCK; LAMBERT, 1987 apud FLEURY; LAVALLE, 1997).

Murphy e Daley (1996) afirmam que o estabelecimento de estratégias globais por parte das empresas tem afetado profundamente a indústria de IFFs. Em resposta à falta de estabilidade do mercado, os IFFs têm se ajustado e procurado ampliar sua oferta de serviços.

Segundo Fleury e Ribeiro (2001a), percebe-se uma tendência crescente de terceirização dos serviços logísticos por parte das empresas exportadoras e importadoras dos mais diversos setores, 
no entanto, ainda há uma pequena oferta de serviços de consultoria visando o projeto de soluções logísticas voltados para clientes potenciais.

Os fatores supracitados (estratégias globais de distribuição; volatilidade do mercado, e tendência à terceirização das operações logísticas), aliados à relativa dispersão e escassez de literatura sobre a atuação dos IFFs, especialmente no mercado brasileiro, justifica a necessidade de uma abordagem estruturada. Nesse sentido, foi desenvolvido um modelo conceitual de suporte à análise da atuação dos IFFs.

O modelo proposto considerou oito fatores: i) âmbito de atuação; ii) oferta de serviços; iii) estratégias competitivas; iv) formas de atuação comercial; v) estrutura física; vi) atividade de origem; vii) sistemas de informação; e viii) setores servidos.

No que tange ao âmbito de atuação, os IFFs podem ser classificados como: regionais, nacionais e globais (FLEURY; RIBEIRO, 2001b; BELFIORE et al, 2005; SINK; LANGLEY; GIBSON, 1996).

Uma empresa com âmbito de atuação regional é, geralmente, forte em apenas uma região de determinado país, tendo uma inserção praticamente insignificante em outras regiões. Pode-se citar como exemplo o maior operador logístico do Rio Grande do Sul que, dentro desse Estado oferece um pacote completo de serviços logísticos, mas, em outras regiões, não possui a mesma estrutura, tendo apenas escritórios pequenos que oferecem serviços básicos, como agenciamento de fretes internacionais e desembaraço aduaneiro. Uma empresa com escritórios ou subagentes nas principais regiões do país, e que tenha condições de oferecer um pacote completo de serviços nessas regiões, pode ser caracterizada como tendo âmbito de atuação nacional. Já o âmbito de atuação global é caracterizado pela presença de estrutura em diversos países, nas principais zonas comerciais do mundo.

Quanto aos serviços, para Kon (2004, p. 25), é possível defini-los como "atividades econômicas que produzem utilidades relativas a tempo, lugar, forma e benefícios psicológicos". Uma forma de agregação de valor aos clientes ocorre por meio dos benefícios provenientes da oferta de serviços de cada empresa. Grönroos (1993), Gianesi e Corrêa (1994) e Johnston e Clark (2002) afirmam que os serviços ao cliente representam uma importante fonte de diferencial competitivo para as empresas, pois se caracterizam como um aspecto intrínseco a praticamente todo e qualquer produto ofertado. Grönroos (1993) também indica que a avaliação com relação a uma organização está relacionada com a oferta ampliada de serviços por essa empresa. Segundo o autor, o pacote básico de serviços pode ser dividido em três tipos: o serviço essencial; os serviços facilitadores e os serviços de suporte. Os clientes, no momento da escolha do fornecedor, analisam o pacote total, incluindo os serviços facilitadores e os de suporte. A facilidade de acesso ao serviço; a interação do usuário com a organização prestadora do serviço e sua participação no processo de 
produção são elementos que complementam o pacote básico, podendo formar uma oferta restrita, intermediária ou ampliada (GRÖNROOS, 1993).

No caso dos IFFs, uma oferta restrita de serviços significa que o IFF oferece somente o transporte internacional. Já um IFF que apresenta uma oferta intermediária de serviços oferece, além do transporte internacional, alguns serviços adicionais, como o desembaraço aduaneiro. Por fim, um IFF com oferta ampliada oferece os principais serviços da cadeia logística, responsabilizando-se e coordenando as operações dos locais de origem aos locais de destino.

Quanto às estratégias competitivas, Porter (1986) as descreve como ações ofensivas ou defensivas para criar uma posição defensável em uma indústria e, assim, obter um retorno sobre o investimento maior para a empresa. Sob essa ótica, o autor define que existem três abordagens estratégicas potencialmente capazes de gerar vantagem competitiva perante a concorrência: liderança em custos; diferenciação do produto ou serviço prestado e enfoque. A liderança em custos determina que a empresa deva ter como objetivo sempre manter o preço mais baixo que o da concorrência. Essa posição implica que a empresa prestadora de serviços logísticos tenha um volume de operações considerável para ter poder de negociação com seus fornecedores e, por vezes, até tenha algum prejuízo inicial até consolidar-se no mercado. Criar algo que seja considerado único no mercado é a estratégia de diferenciação por produto ou serviço prestado. Porter (1986) afirma que a diferenciação, se alcançada, é uma estratégia viável para obter recursos com margem de lucro maior, excluindo a necessidade de posição de baixo custo, pois proporciona isolamento contra a concorrência devido à lealdade dos clientes em relação à marca e à menor sensibilidade ao preço. A última estratégia genérica é o enfoque em determinado grupo comprador, segmento ou mercado geográfico (PORTER, 1986). Essa estratégia é baseada na idéia de que a empresa é capaz de atender melhor seu alvo estratégico do que a concorrência pode fazer de forma abrangente. A empresa atinge a vantagem ao satisfazer melhor as necessidades de seu público-alvo ou por obter menores custos nesse alvo.

Quanto às formas de atuação comercial de um IFF, é possível identificar dois grupos: os que têm atuação discreta no mercado e os que têm atuação agressiva (RUMELT; SCHENDEL; TEECE, 1998; DANIELL, 2004). Os IFFs que apresentam atuação comercial discreta, normalmente, são aqueles que já têm a sua marca reconhecida no mercado. Eles não precisam fazer visitas tão freqüentes aos clientes, pois estes já o conhecem em virtude de sua marca ser forte, diferentemente dos que têm uma atuação comercial agressiva, que não possuem uma marca forte tampouco reconhecida e, por isso, necessitam maior exposição ao mercado para conquistar determinada fatia do mesmo.

No que se refere às características da estrutura física, existem basicamente três grupos (AFRICK; CALKINS, 1994): i) o grupo dos prestadores de serviços logísticos baseados em sua 
própria estrutura física, que possuem e operam ativos de transporte e de armazenagem; ii) o grupo dos não baseados em estrutura física própria, que subcontratam os ativos e sua operação com terceiros; e iii) o grupo dos PSLs híbridos que, apesar de possuírem ativos físicos, também contratam ativos de terceiros. Essas empresas, em geral, são partes de um grupo onde as empresas "mães" possuem ativos logísticos e as empresas "filhas" possuem os recursos humanos qualificados e os sistemas de informação.

Os IFFs também podem ser segmentados por sua atividade de origem (FLEURY; RIBEIRO, 2001b; BELFIORE et al, 2005). Existem diversas origens possíveis: transportadoras; empresas especializadas em armazenagem; entrega expressa ou courier; indústrias; despachantes aduaneiros ou mesmo agentes de cargas.

No que diz respeito ao sistema de informações, o fluxo eficaz é um elemento de grande importância nas operações logísticas. Pedidos de clientes e de ressuprimento; necessidades de estoque; movimentações nos armazéns; documentação de transporte e faturas são algumas das formas mais comuns de informações logísticas (NAZÁRIO, 1999). Segundo o autor, hoje em dia existem três razões que justificam a importância da informação precisa e na hora exata para sistemas logísticos eficazes: i) as empresas percebem que informações sobre status do pedido, disponibilidade de produtos, programação de entrega e fatura são elementos necessários do serviço total ao cliente; ii) com a meta de redução do estoque total na cadeia de suprimentos, é perceptível que a informação precisa e em tempo pode reduzir de forma eficaz as necessidades de estoque e de recursos humanos; iii) a informação aumenta a flexibilidade, permitindo identificar (qual, quanto, como, quando e onde) os recursos que podem ser utilizados para que se obtenha vantagem estratégica. Basicamente, os sistemas de informações logísticas funcionam como elos que ligam as atividades em um processo integrado, combinando hardware e software para medir, controlar e gerenciar as operações logísticas. Essas operações ocorrem tanto dentro de uma empresa específica como ao longo de toda a cadeia de suprimentos. Esses sistemas possuem quatro níveis funcionais: sistema transacional; controle gerencial; apoio à decisão e planejamento estratégico (NAZÁRIO, 1999).

O sistema transacional é a base para as operações logísticas e a fonte para atividades de planejamento e coordenação. O sistema de controle gerencial permite que se utilizem as informações disponíveis no sistema transacional para o gerenciamento das atividades logísticas. Já o de apoio à decisão caracteriza-se pelo uso de softwares para apoiar atividades operacionais, táticas e estratégicas que possuem elevado nível de complexidade. Por fim, o sistema de planejamento estratégico das informações logísticas é a base para o desenvolvimento e o aperfeiçoamento de estratégias logísticas. 
No que tange aos setores servidos pela indústria dos International Freight Forwarders e prestadores de serviços logísticos em geral, Fleury (2004) afirma que os principais setores, considerando o valor gasto com terceiros na execução das atividades logísticas, são: químico e petroquímico; alimentos; automotivo; siderurgia e metalurgia; e papel e celulose. Dito isso, pode-se construir um quadro contendo os diferentes fatores e dimensões concernentes ao posicionamento competitivo dos IFFs (Figura 1).

Figura 1 - Modelo conceitual de análise de International Freight Forwarders

\begin{tabular}{|c|c|}
\hline Fator & Dimensões \\
\hline Âmbito de Atuação & Regional - Nacional - Global \\
\hline Oferta de Serviços & Restrita - Intermediária - Ampliada \\
\hline Estratégias Competitivas & Liderança em custos - Diferenciação por serviços - Enfoque \\
\hline $\begin{array}{l}\text { Formas de Atuação } \\
\text { Comercial }\end{array}$ & Discreta - Agressiva \\
\hline $\begin{array}{l}\text { Característica da Estrutura } \\
\text { Física } \\
\end{array}$ & Baseada em estrutura própria - Híbrida - Não baseada em estrutura própria \\
\hline Atividade de Origem & $\begin{array}{c}\text { Agente de Cargas - Transportadora - Despachante aduaneiro - Courier - } \\
\text { Empresa de armazenagem - Indústria }\end{array}$ \\
\hline Sistemas de Informação & $\begin{array}{c}\text { Transacional - Controle gerencial - Apoio à decisão - Planejamento } \\
\text { estratégico }\end{array}$ \\
\hline Setores Servidos & $\begin{array}{c}\text { Químico e Petroquímico - Alimentos - Automotivo e autopeças - Papel e } \\
\text { celulose - Siderurgia e metalurgia - Bebidas - Tecnologia e } \\
\text { Telecomunicações - Eletro-eletrônico - Higiene e limpeza }\end{array}$ \\
\hline
\end{tabular}

Fonte: os autores

Uma característica dessa figura é que, em função da proposta teórica, diferentes fatores apresentam diferentes números de dimensões. Isso, no entanto, não compromete a análise da atuação dos IFFs.

\section{Procedimentos metodológicos}

No presente estudo, para a obtenção dos dados primários, foi utilizado um questionário estruturado, contendo perguntas para: i) caracterizar o respondente, principalmente no que tange à sua experiência na área; ii) avaliar o posicionamento competitivo dos IFFs contratados por sua empresa, segundo os fatores e dimensões do modelo conceitual proposto; e iii) identificar a adequação das diferentes dimensões do posicionamento competitivo dos IFFs, conforme modelo proposto, às demandas das empresas respondentes.

Antes de ser enviado aos respondentes por meio de correio eletrônico, o questionário foi prétestado em uma amostra de cinco profissionais com experiência na contratação de serviços de IFFs, escolhidos por acessibilidade e conveniência. Com isso, pôde ser revisado o instrumento e efetuados os ajustes necessários. A amostra foi composta por 26 empresas exportadoras, localizadas no Rio Grande do Sul e cadastradas na base de dados da Federação das Indústrias do Estado do Rio 
Grande do Sul (Fiergs). O questionário foi respondido em cada empresa pelo profissional responsável pela contratação de serviços de freight forwarding.

Concluída a coleta, os dados foram tabulados e analisados. Nas análises, inicialmente, foram utilizados procedimentos de estatística descritiva. Em um segundo momento, os dados foram submetidos à análise multivariada, utilizando-se o método de regressão linear múltipla. Na análise de regressão, utilizou-se como variável dependente a adequação geral do posicionamento do IFF à demanda da empresa exportadora e, como variáveis independentes, a adequação de cada um dos oito fatores à demanda da organização. Buscou-se, com isso, identificar, entre os fatores do modelo conceitual, os mais relacionados com a adequação geral do posicionamento competitivo dos IFFs. A escala utilizada variou de 1 a 5 , sendo o extremo inferior caracterizado como "totalmente inadequado" e o extremo superior como "totalmente adequado".

\section{Análise de dados e resultados}

No que se refere ao tempo de experiência, os resultados mostraram que a maioria dos respondentes já tem uma experiência considerável de mercado.

\begin{tabular}{cc}
\multicolumn{2}{c}{ Tabela 1 - Tempo de Experiência } \\
\hline Experiência & $\mathbf{N}^{\mathbf{0}}$ de respostas \\
\hline 1 a 5 anos & 11 \\
6 a 10 anos & 6 \\
11 a 15 anos & 6 \\
Mais de 15 anos & 3 \\
\hline Total & $\mathbf{2 6}$ \\
\hline
\end{tabular}

Fonte: Dados da pesquisa

No fator âmbito de atuação, a grande maioria dos respondentes indicou que contrata IFFs com atuação global, o que denota uma preferência por empresas que possuam estrutura própria em diversos países. Apenas dois respondentes indicaram que trabalham com IFFs de atuação nacional.

Tabela 2 - Âmbito de Atuação

\begin{tabular}{cc}
\hline Âmbito de Atuação & $\mathbf{N}^{\mathbf{0}}$ de respostas \\
\hline Regional & 0 \\
Nacional & 2 \\
Global & 24 \\
Não sabe/NR & 0 \\
\hline Total & $\mathbf{2 6}$ \\
\hline
\end{tabular}

Fonte: Dados da pesquisa

No que tange à oferta de serviços, pôde-se perceber uma preferência por empresas que ofereçam todos os serviços da cadeia logística com sua própria estrutura, porém ainda existem muitas empresas que trabalham com IFFs que oferecem apenas os serviços de agenciamento de cargas e desembaraço aduaneiro, terceirizando o restante. 
Tabela 3 - Oferta de Serviços

\begin{tabular}{cc}
\hline Oferta de Serviços & $\mathbf{N}^{\mathbf{0}}$ de respostas \\
\hline Restrita & 2 \\
Intermediária & 10 \\
Ampliada & 15 \\
Não sabe/NR & 0 \\
\hline Total & $\mathbf{2 7}$
\end{tabular}

Fonte: Dados da pesquisa

Cabe salientar neste aspecto que um respondente citou mais de um tipo de oferta de serviços, gerando um total maior de respostas (27).

Quanto às estratégias competitivas, a maioria dos respondentes indicou que trabalha com IFFs que utilizam a estratégia de diferenciação por serviços. Porém, pode-se perceber que alguns respondentes indicaram que seus prestadores de serviço possuem mais de uma estratégia competitiva, o que indica falta de conhecimento dos respondentes quanto a essa questão ou uma indefinição dos IFFs no que se refere à estratégia competitiva. Tal indefinição é definida por Porter (1986) como a "estratégia do meio-termo" e pode significar um risco para uma empresa no momento em que a mesma venha a se defrontar com competidores focados em estratégias específicas.

Tabela 4 - Estratégias Competitivas

\begin{tabular}{cc}
\hline Estratégias Competitivas & Respostas \\
\hline Liderança em custos & 7 \\
Diferenciação por serviços & 18 \\
Enfoque & 4 \\
Não sabe/NR & 0 \\
\hline Total & $\mathbf{2 9}$ \\
\hline
\end{tabular}

Fonte: Dados da pesquisa

Sobre o fator formas de atuação comercial, o resultado obtido indica equilíbrio, com uma leve predominância de empresas optando pela contratação de IFFs que atuem de maneira discreta no que tange à sua atuação comercial. Isso revela uma preferência por empresas que já tenham uma marca estabelecida e conhecida no mercado.

Tabela 5 - Formas de Atuação Comercial

\begin{tabular}{cc}
\hline Formas de Atuação Comercial & $\mathbf{N}^{\mathbf{0}}$ de respostas \\
\hline Discreta & 14 \\
Agressiva & 11 \\
Não sabe/NR & 1 \\
\hline Total & $\mathbf{2 6}$ \\
\hline
\end{tabular}

Fonte: Dados da pesquisa

Já no que se refere às características da estrutura física, a grande maioria dos respondentes trabalha com IFFs de estrutura híbrida. O número de exportadores que trabalham com IFFs que não possuem ativos e que, portanto, terceirizam suas operações, ficou muito abaixo dos outros itens. Cabe salientar que dois respondentes citaram mais de um tipo de estrutura física. 
Tabela 6 - Características da Estrutura Física

\begin{tabular}{lc}
\hline Características da Estrutura Física & $\mathbf{N}^{\mathbf{0}}$ de respostas \\
\hline Baseada em ativos & 8 \\
Híbrida & 14 \\
Não baseada em ativos & 4 \\
Não sabe/NR & 2 \\
\hline Total & $\mathbf{2 8}$
\end{tabular}

Fonte: Dados da pesquisa

No fator atividade de origem do IFF, pode-se perceber uma preferência por prestadores que tenham iniciado suas atividades já como agentes de cargas.

Tabela 7 - Atividade de Origem

\begin{tabular}{lc}
\hline Atividade de Origem & $\mathbf{N}^{\mathbf{0}}$ de Respostas \\
\hline Agente de Cargas & 20 \\
Transportadora & 3 \\
Despachante Aduaneiro & 8 \\
Courier & 1 \\
Armazenagem & 2 \\
Indústria & 0 \\
Outra & 0 \\
Não sabe/NR & 1 \\
\hline Total & $\mathbf{3 5}$ \\
\hline
\end{tabular}

Fonte: Dados da pesquisa

Pode-se considerar que o know-how de uma empresa tenha alguma relação com a sua atividade de origem e isso pode ter influenciado os respondentes no momento da contratação do IFF. Percebe-se nesse quesito a indicação de mais de uma atividade de origem por alguns respondentes, elevando o número de respostas para 35.

Quanto ao sistema de informação, grande parte dos respondentes não soube indicar qual o sistema utilizado pelo IFF contratado por sua empresa. Isso pode ser interpretado de duas maneiras: i) os respondentes não têm conhecimento suficiente sobre os sistemas de informação utilizados para dar uma resposta clara; ou, ii) os IFFs gaúchos não possuem um sistema de informação integrado com a empresa contratante. De qualquer modo, apenas um respondente indicou que o IFF contratado por sua empresa utiliza sistema de apoio à decisão; houve uma similaridade na quantidade de respostas para os sistemas transacional e de planejamento estratégico, com 19\% cada; e o sistema de controle gerencial foi citado por seis respondentes $(23 \%)$.

Tabela 8: Sistemas de Informação

\begin{tabular}{ll}
\hline Sistemas de Informação & $\mathbf{N}^{\mathbf{0}}$ de respostas \\
\hline Sistema transacional & 5 \\
Controle gerencial & 6 \\
Apoio à decisão & 1 \\
Planejamento estratégico & 5 \\
Não sabe/NR & 9 \\
\hline Total & $\mathbf{2 6}$ \\
\hline Fonte: Dados da pesquisa &
\end{tabular}


Já no que tange ao fator setores servidos, houve uma grande variação nas respostas. Além disso, muitos respondentes não souberam responder qual o principal setor servido pelo IFF, o que mostra que este fator não é tão importante no momento da contratação. Pode-se observar, contudo, destaque para dois setores: alimentos e siderurgia e metalurgia, ambos representando aproximadamente $17 \%$ do total de respostas.

Tabela 9 - Setores servidos

\begin{tabular}{lcc}
\hline Setores Servidos & $\mathbf{N}^{\mathbf{0}}$ de respostas & $\mathbf{\%}$ \\
\hline Químico e petroquímico & 0 & 0,0 \\
Alimentos & 5 & 16,7 \\
Automotivo e autopeças & 1 & 3,3 \\
Papel e celulose & 1 & 3,3 \\
Siderurgia e metalurgia & 5 & 16,7 \\
Bebidas & 0 & 0,0 \\
Tecnologia e telecomunicações & 0 & 0,0 \\
Eletrônico & 2 & 6,7 \\
Higiene e limpeza & 0 & 0,0 \\
Outro & 7 & 23,3 \\
Não sabe/NR & 9 & 30,0 \\
\hline Total & $\mathbf{3 0}$ & $\mathbf{1 0 0 , 0}$ \\
\hline
\end{tabular}

Fonte: Dados da pesquisa

Quanto ao nível de adequação em relação ao modelo de IFF contratado, as respostas obtidas indicaram uma adequação geral média de 3,73 e um desvio-padrão de 0,67. É possível afirmar que a adequação geral é elevada, uma vez que a escala utilizada variava entre 1 (totalmente inadequado) e 5 (totalmente adequado). Os fatores com níveis de adequação mais elevados foram o âmbito de atuação $(4,00)$, a oferta de serviços e as características da estrutura física (ambos com 3,96). Por outro lado, os fatores com pior avaliação foram as estratégias competitivas $(3,62)$ e os setores servidos $(3,64)$. Pode-se considerar, ainda assim, que, considerando a escala utilizada, esses fatores obtiveram níveis de adequação altos. Os demais atributos ficaram com uma adequação média variando entre 3,71 e 3,80. Os dados demonstram que os respondentes consideram adequado o posicionamento competitivo adotado pelos IFFs contratados.

Tabela 10 - Níveis de adequação atribuídos pelos respondentes

\begin{tabular}{lcc}
\hline Fatores & Média & Desvio Padrão \\
\hline Âmbito de Atuação & 4,00 & 0,63 \\
Oferta de Serviços & 3,96 & 0,77 \\
Estratégias Competitivas & 3,62 & 0,57 \\
Formas de Atuação Comercial & 3,73 & 0,67 \\
Características da Estrutura Física & 3,96 & 0,53 \\
Atividade de Origem & 3,80 & 0,75 \\
Sistemas de Informação & 3,71 & 0,92 \\
Setores Servidos & 3,64 & 0,53 \\
\hline Adequação Geral & $\mathbf{3 , 7 3}$ & $\mathbf{0 , 6 7}$
\end{tabular}

Fonte: Dados da pesquisa 
A relação entre a adequação em cada fator e a adequação geral atribuída pelos respondentes foi medida por meio de regressão linear múltipla, tendo sido considerada a adequação geral como variável dependente e os diferentes fatores como variáveis independentes.

Inicialmente, rodou-se a regressão com as oito variáveis contempladas no modelo $(\mathrm{AA}=$ âmbito de atuação; $\mathrm{OS}$ = oferta de serviços; $\mathrm{EC}=$ estratégias competitivas; $\mathrm{AC}=$ formas de atuação comercial; $\mathrm{EF}=$ características da estrutura física; $\mathrm{AO}=$ atividade de origem; $\mathrm{SI}=$ sistemas de informação e $\mathrm{SS}=$ setores servidos). No entanto, somente as variáveis $\mathrm{AA}, \mathrm{OS}, \mathrm{AC}$ e EF apresentaram significância estatística. Por essa razão, foi gerado um modelo refinado, considerando-se apenas as quatro variáveis significativas. Os resultados gerais da regressão são apresentados na tabela 11. Como se pode observar, o modelo é capaz de explicar 85,36\% da adequação do posicionamento competitivo adotados pelos IFFs no mercado gaúcho.

Tabela 11 - Estatística da regressão com os quatro fatores mais significantes

\begin{tabular}{lr}
\hline \multicolumn{2}{c}{ Estatística de regressão } \\
\hline R múltiplo & 0,923917446 \\
R-Quadrado & 0,853623447 \\
R-quadrado ajustado & 0,825742199 \\
Erro padrão & 0,278348162 \\
\hline Observações & 26 \\
\hline Fonte: Dados da pesquisa
\end{tabular}

As variáveis âmbito de atuação (AA), oferta de serviços (OS) e formas de atuação comercial (AC) apresentaram significância estatística a um nível de confiança de pelo menos 97,66\%. Já a variável características da estrutura física (EF) mostrou-se significativa a 83,97\%. A tabela 12 apresenta os coeficientes das quatro variáveis no modelo refinado e o valor P de cada variável.

\begin{tabular}{lcc}
\multicolumn{3}{c}{ Tabela 12 - Coeficientes e valor P de cada variável } \\
\hline & Coeficientes & valor-P \\
\hline Interseção & $-0,896128477$ & 0,1040734 \\
AA & 0,369752977 & 0,0106065 \\
OS & 0,306825762 & 0,0233819 \\
AC & 0,344355193 & 0,0054041 \\
EF & 0,163617602 & 0,1602639 \\
\hline
\end{tabular}

Fonte: Dados da pesquisa

A equação que descreve o modelo é a seguinte:

$\mathrm{AG}=-0,8961+0,3697 * \mathrm{AA}+0,3068^{*} \mathrm{OS}+0,3445^{*} \mathrm{AC}+0,1636^{*} \mathrm{EF}$

Onde:

AG: Adequação Geral;

AA: Âmbito de Atuação;

OS: Oferta de Serviços;

AC: Formas de Atuação Comercial;

EF: Características da Estrutura Física. 
O modelo mostra que a adequação geral do posicionamento competitivo dos IFFs contratados (variável dependente) à demanda dos exportadores pertencentes à amostra é significativamente influenciada pelos fatores âmbito de atuação (AA), oferta de serviços (OS), formas de atuação comercial (AC) e características da estrutura física (EF). Tem-se, portanto, que a criação de valor para os exportadores gaúchos, no que diz respeito à contratação de IFFs, depende muito do posicionamento do IFF em relação a esses fatores.

\section{Considerações finais}

Com os resultados obtidos, foi possível identificar o posicionamento competitivo adotado pelos principais IFFs do mercado gaúcho. Em alguns fatores, como âmbito de atuação, oferta de serviços, estratégias competitivas, características da estrutura física e atividade de origem, está muito claro o posicionamento adotado pelas empresas e demandado por seus clientes. Os demais fatores apresentaram maior dispersão nos resultados.

Quanto ao posicionamento adotado pelas empresas atuantes nesse setor em cada fator considerado no modelo conceitual proposto, segundo a pesquisa realizada, pode-se concluir o seguinte: i) o âmbito de atuação dos IFFs é predominantemente global; ii) há uma preferência por IFFs que tenham uma oferta ampliada de serviços (embora os IFFs com oferta intermediária, que terceirizam parte dos serviços, também tenham obtido um número expressivo de respostas); iii) no que diz respeito às estratégias competitivas, houve uma predominância da diferenciação por serviços; iv) quanto às características da estrutura física, a maioria dos respondentes indicou que trabalha com IFFs de estrutura híbrida; v) no fator atividade de origem, mais de $50 \%$ das empresas responderam que contratam IFFs que já tenham iniciado suas atividades como agentes de carga, o que sugere que o know-how é algo valorizado nesse mercado; vi) o fator formas de atuação comercial teve $54 \%$ de respostas para IFFs com atuação discreta e $42 \%$ para IFFs com atuação agressiva; vii) o fator sistemas de informação apresentou grande dispersão nas respostas, sendo que um número particularmente grande de respondentes (35\%) não souberam ou simplesmente não responderam a essa questão; e viii) o fator setores servidos, da mesma forma que o anterior, também apresentou respostas variadas e um número significativo de respondentes que não souberam ou não responderam à questão (30\%).

A análise de regressão indicou os fatores que apresentaram relação mais significativa com a adequação geral do posicionamento competitivo dos IFFs às demandas dos exportadores pertencentes à amostra, sendo eles: i) âmbito de atuação; ii) oferta de serviços; iii) formas de atuação comercial e iv) características da estrutura física.

Com isso, os IFFs podem não só reforçar os atributos desejáveis como trabalhar aquelas questões consideradas não tão relevantes para reconfigurar o desenho de seus serviços oferecidos. 
Paralelamente, as empresas usuárias desses serviços, com este trabalho, podem melhorar o seu conhecimento do entorno competitivo no setor estudado.

\begin{abstract}
The present study identifies the competitive positioning of International Freight Forwarders (IFFs) based on Rio Grande do Sul exporter's demand of this kind of services. These logistics providers, also known as international cargo agents, have a crucial importance to the correctness and efficiency of international cargo transportation, mainly due to the today's complexity and amplitude of global logistics operations. For this purpose, based on the International Freight Forwarders conceptual model, made by literature review of this study area, it was developed and sent a questionnaire to a export companies sample, extract from the Federação das Indústrias do Estado do Rio Grande do Sul (Fiergs) database. Once received and organized, the data were submitted to descriptive statistics techniques and multiple regression analysis. This made possible to analyze the suitability of international freight forwarder's competitive positioning to the exporter's demand and identify the determinant factors of that positioning. The results obtained are relevant and give support to the Rio Grande do Sul International Freight Forwarders industry analyze, the IFFs strategy conception and the exporter's selection of these services providers.
\end{abstract}

Key Words: Logistics Providers; International Freight Forwarders; Competitive Positioning.

\title{
Referências
}

AFRICK, J. M; CALKINS, C. S. Does Asset Ownership Mean Better Service?. Transportation \& Distribution, v. 35, n. 5, p. 46-61, 1994.

ALBA, U. Gestión y control en la nueva economía. Madrid: Ramón Areces, 2006.

ANDERSON, P. Origem da modernidade. Rio de Janeiro: Zahar, 1999.

AVILA, G. Estamos na quinta fase da logística? Características e paradigmas da gestão total da cadeia de negócios. São Paulo: SIMPOI 2006 - FGV - EASP.

BELFIORE, P. P.; MARQUES, J. J.; FÁVERO, L. P. L.; ROTONDARO, R. G. Avaliação do nível de serviço de operadores logísticos no Brasil: uma aplicação de análise fatorial e regressão logística binária. Seminários em Administração FEA-USP. São Paulo, 11 e 12 de agosto, 2005. Disponível em:

<http://www.ead.fea.usp.br/semead/8semead/resultado-/an_resumo.asp?cod_trabalho=27>. Acesso em: 04.mar.2012.

DANIELL, M. Strategy. New York: Palgrave, 2004.

cross ref

DAY, G. A empresa orientada para o mercado. Porto Alegre: Bookman, 2001.

FIATA. Freight forwarders adopt an official description of “freight forwarding and logistics services". 2004. Disponível em: <http://www.fiata.com/uploads/media/CL0406_04-.pdf>. Acesso em: 04 mar. 2012.

FLEURY, P. F. A indústria de provedores de serviços logísticos no Brasil: analisando oferta e demanda de serviços. Instituto de Logística e Supply Chain (ILOS), 2004. Disponível em:

<http://www.ilos.com.br/web/index.php?option=com_content\&task=view\&id=724\&-Itemid=74\&lang=br>. Acesso em: 04.mar.2012.

FLEURY, P. F.; LAVALLE, C. O estágio de evolução do suprimento internacional em empresas brasileiras: a perspectiva dos “international freight forwarders”. Instituto de Logística e Supply Chain (ILOS), 1997. Disponível em: <http://www.ilos.com.br/web-/index.php?option=com_content\&task=view\&id=1128\&Itemid=74\&lang=br>. Acesso em: 04. mar. 2012. 
FLEURY, P. F.; RIBEIRO, A. A indústria de operadores logísticos no Brasil: uma análise dos principais operadores. Instituto de Logística e Supply Chain (ILOS), 2001-a. Disponível em:

<http://www.ilos.com.br/web/index.php?option=com_content\&task=view\&id=1097\&-Itemid=74\&lang=br>. Acesso em: 04.mar.2012.

FLEURY, P. F.; RIBEIRO, A. A indústria de prestadores de serviços logísticos no Brasil: caracterizando os principais operadores. In: XXV Encontro Anual da Anpad (Enanpad). Campinas, 2001. Anais do XXV Enapad, Campinas, 2001.

GIANESI, I.; CORRÊA, H. Administração estratégica de serviços. São Paulo: Atlas, 1994.

GRÖNROOS, C. Marketing - gerenciamento e serviços: a competição por serviços na hora da verdade. Rio de Janeiro: Campus, 1993.

HENRICH, V. R. Correlação entre a indústria de freight forwarding no Brasil e no mundo. São Leopoldo: UNISINOS, 1998.

JOHNSTON, R.; CLARK, G. Administração de operações e serviços. São Paulo: Atlas, 2002.

KON, A. Economia de serviços. Rio de Janeiro: Campus, 2004.

MILAN, G. S. Diferenciação por serviços e posicionamento competitivo. In: VIEIRA, G. B. B. Logística e distribuição física internacional: teoria e pesquisas. São Paulo: Aduaneiras, 2006.

MURPHY, P.; DALEY, J. A preliminary analysis of the strategies of international freight forwarders. Transportation Journal, v. 35, n. 4, p. 5-11, 1996.

MURPHY, P.; DALEY, J. Investigating selection criteria for international freight forwarders. Transportation Journal, v. 37, n. 1, p. 29-36, 1997.

PORTER, M. Estratégia competitiva. Rio de Janeiro: Campus, 1986.

POSSAS, S. Concorrência e competitividade. São Paulo: Hucitec, 1999.

RUMELT, R. SCHENDEL, D.; TEECE, D. Questões fundamentais de estratégia. Lisboa: Bertrand, 1998.In: SIMCHI-LEVI, D.; KAMINSKY, P.; SIMCHI-LEVI, E. Managing the supply chain. New York: Mc Graw-Hill, 2004.

SINK, H. L.; LANGLEY, J. C.; GIBSON, B. J. Buyer observations of the US third-party logistics market. International Journal of Physical Distribution \& Logistics Management, v. 26, n. 3, p. 38-46, 1996.

cross ref

ZALTMAN, G. Cómo piensan los consumidores. Barcelona: Urano, 2004.

\section{Dados dos Autores:}

Nome completo: Guilherme Bergmann Borges Vieira

Filiação institucional: Universidade de Caxias do Sul (UCS)

Departamento: Centro de Ciências Econômicas, Contábeis e de Comércio Internacional (CECI)

Função ou cargo ocupado: Professor assistente

Endereço completo para correspondência: Av. Venâncio Aires, 134/ 612. Bairro Cidade Baixa.

Porto Alegre - RS, Brasil. CEP: 90.040-190.

Telefone para contato: (51) 99448504

e-mail: gbvieira@cpovo.net 
Nome completo: Carlos Honorato Schuch Santos

Filiação institucional: Universidade Federal de Santa Maria (UFSM)

Departamento: Departamento de Engenharia de Produção

Função ou cargo ocupado: Professor adjunto

Endereço completo para correspondência: Rua Tomás Flores, nº 340. Bairro Bonfim. Porto Alegre RS, Brasil. CEP: 90.035-200

Telefones para contato: (51) 99448504

e-mail: chonorato@terra.com.br

Recebido em: $14 / 08 / 2012$

Aceito em: 01/10/2012 